\title{
Prof. Johan F. Vansteenkiste: bring immunotherapy to frontline therapy in order to cure more patients
}

Received: 05 December 2018; Accepted: 23 December 2018; Published: 24 December 2018.

doi: $10.21037 /$ shc.2018.12.03

View this article at: http://dx.doi.org/10.21037/shc.2018.12.03

\section{Editor's note}

The 1st China-Eastern Europe International Forum on Thoracic Disease was successfully held in Shanghai, China during Nov. 2-3, under the cooperation among Shanghai Chest Hospital, Shanghai Hospital Association, and General University Hospital in Prague, Czech Republic. Centered novel technologies and research advances in the diagnosis and treatment of thoracic disease, world-renowned experts came together, talking and sharing the latest progress, aiming at promoting the academic communication.

Prof. Johan F. Vansteenkiste from University Hospital KU Leuven, Belgium presented a speech on "Role and prospects of Immunotherapy in the integrated oncology", showing the increasingly important role of immunotherapy in the treatment of oncology in recent years and its bright future (Figure 1). During the meeting, Shanghai Chest took the honor to invite Prof. Vansteenkiste to have an interview onsite, talking about his view on immunotherapy (Figure 2). Serving as principal investigator (PI) or co-investigator in several clinical trials in the area of lung cancer, Prof. Vansteenkiste also shared the challenges that he and his team has ever encountered, hoping that his experience can help the other peers. Watch the video to learn more information (Figure 3).

\section{Expert's introduction}

Johan F. Vansteenkiste graduated in 1982 from the Catholic University of Leuven before becoming a boardcertified specialist in Internal Medicine and Pulmonology. He had additional training in Respiratory Oncology at the European School of Oncology in Milan, Italy, and in Respiratory Endoscopy at the Laser Centre in Marseille, France, before gaining his $\mathrm{PhD}$ in Leuven in 1996. He is head of the Respiratory Oncology Unit and its Clinical Trial Unit since 1995, and full professor at the Faculty of Medicine in Leuven. He is an active member of different national and international societies such as ESMO, IASLC, ASCO, ERS, and others. He was Secretary of the Thoracic

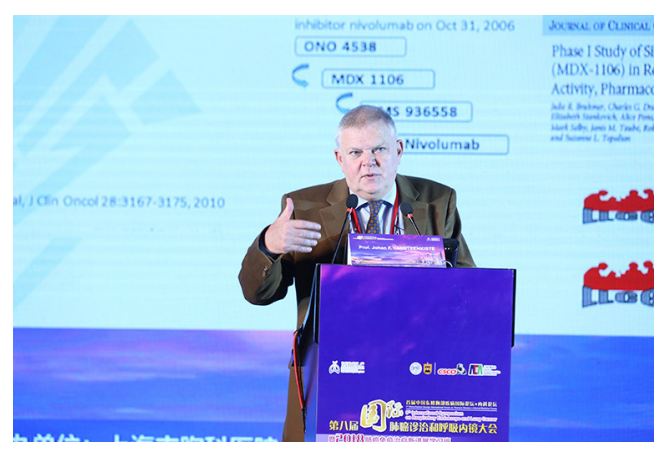

Figure 1 Prof. Johan F. Vansteenkiste.

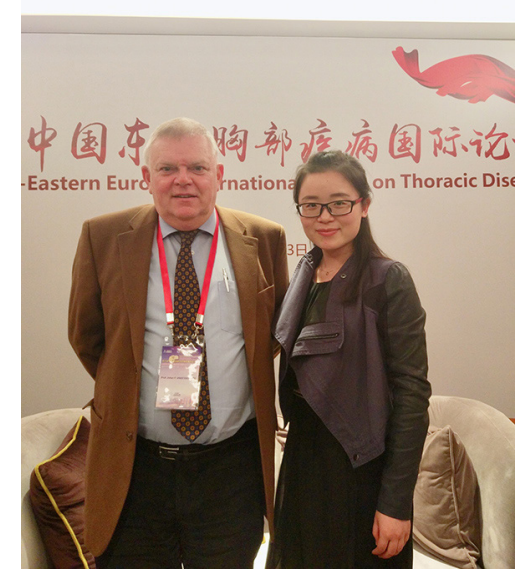

Figure 2 The Editor and Prof. Johan F. Vansteenkiste.

Oncology Assembly of the ERS and member of the ERS School Board from 2009-2012, member of the Board of Directors of IASLC in 2009-2013, and is a member of the ESMO Lung Educational Group and Guidelines Group. He is the PI or co-investigator in several clinical trials in the area of lung cancer. He was an associate editor for Respiration and Fournal of Thoracic Oncology, now is thoracic editor at Annals of Oncology, and is a reviewer for several oncology journals. He is author or co-author of more than 300 peer-reviewed 


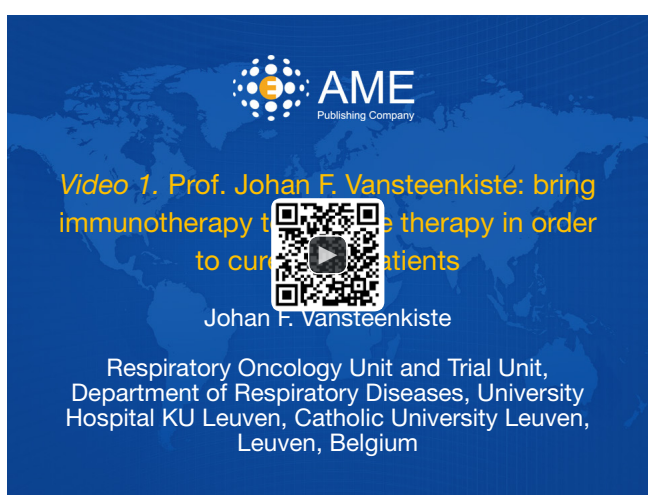

Figure 3 Prof. Johan F. Vansteenkiste: bring immunotherapy to frontline therapy in order to cure more patients (1).

Available online: http://www.asvide.com/article/view/29063

papers and book chapters on Respiratory Oncology.

\section{Immunotherapy}

2018 is an extraordinary year. The 2018 Nobel Prize in Physiology or Medicine was awarded jointly to Prof. James P. Allison and Prof. Tasuku Honjo, in recognition of their outstanding contribution to tumor immunology. Looking back to $1950 \mathrm{~s}$, it was first documented that the immune system has a controlling role, a surveillance role for cancer. In the year of 2006, after the initial basic researches on the immune system and its role in cancer, scientists came to the very first patients treated with immunotherapy in clinical practice. From these initial trials that were usually in heavily pretreated lung cancer patients, longterm results have now been received. In fact, $16-18 \%$ of the patients are alive at five years, which means that what immunotherapy does for cancer patient is clearly different from chemotherapy. Prof. Vansteenkiste said, "What is ongoing now is bringing immunotherapy to frontline therapy for metastatic patients, and bringing immunotherapy to nonmetastatic stages in order to cure more patients. So, it's an exciting development."

When it comes to the future of immunotherapy, Prof. Vansteenkiste thinks the future is now already. What we see in patients with metastatic lung cancer is that immunotherapy, either combined with chemotherapy or on its own in patients that have good markers for immunosensitivity, has a very important role already now in improving overall survival. Some patients achieve long-term survival. It's a further subject to improve combinations with chemotherapy, perhaps combinations with targeted agents.

According to Prof. Vansteenkiste, clinicians should care about transferring the benefits of immunotherapy to improve cure rates in patients with non-metastatic lung cancer. The next move will go the early stage patients. Now about $50-60 \%$ of these patients are cured with surgery and chemotherapy, but bringing in immunotherapy has the hope to further improve on these results. It will take some years before we know, because long follow-up is needed in patients with early stage non-small cell lung carcinoma (NSCLC). Trials are ongoing to see if we can improve the cure rate of surgical patients by combining immunotherapy either preoperatively or postoperatively.

\section{Challenge in clinical trials}

One of the important challenges in first-line clinical trials for patients with advanced lung cancer is time. In clinical trials, patients' tissues need sending to a central lab for an analysis. This induces waiting time (2-3 weeks) for patients who are in their first-line setting. These patients want to start their therapy and do not want to wait three more weeks. Thus, Prof. Vansteenkiste thought it's important in clinical trials that collected tissues but did not make patients wait to start the therapy based on a central lab result. It is one of the biggest challenges that Prof. Vansteenkiste has seen nowadays.

\section{Collaboration with medical centers in China}

When talking about the collaboration with medical centers in China, especially in thoracic oncology, Prof. Vansteenkiste thought clinical trials and education were the two aspects. On the one hand, there are a very high number of patients with lung cancer in China. Therefore, it's a good opportunity to collaborate with Chinese centers with good clinical practice, which is already happening. The other opportunity is education. Taking the example of immunotherapy, it is now being introduced in clinical practice in China, so it will be new for Chinese doctors who did not take part in clinical trials. Prof. Vansteenkiste's team had the same experience $2-3$ years ago. Doctors, oncologists, pulmonologists had to learn how to work with immunotherapy, when and in which patients to start, how to assess efficacy, how to watch for toxicities. There are a lot of educational roles that Prof. Vansteenkiste and his team can play in different media and meetings. It's a continuing 
learning curve, but Prof. Vansteenkiste is happy to share knowledge with Chinese doctors.

\section{Interview questions}

(I) What's the role of immunotherapy in the integrated oncology?

(II) What do you think is the future of immunotherapy?

(III) Any other promising treatment for lung cancer?

(IV) You are PI or Co-PI in several clinical trials in the area of lung cancer. Looking back, can you share with us the challenges you have encountered in conducting the clinical trials? How did you overcome it?

(V) How do you see the collaboration with China medical professionals?

\section{Acknowledgments}

Funding: None.

\section{Footnote}

Provenance and Peer Review: This article was commissioned by the Editorial Office, Shanghai Chest. The article did not undergo external peer review.

Conflicts of Interest: The author has completed the ICMJE

doi: 10.21037/shc.2018.12.03

Cite this article as: Wang MJ. Prof. Johan F. Vansteenkiste: bring immunotherapy to frontline therapy in order to cure more patients. Shanghai Chest 2018;2:99. uniform disclosure form (available at http://dx.doi. org/10.21037/shc.2018.12.03). The author has no other conflicts of interest to declare.

Ethical Statement: The author is accountable for all aspects of the work in ensuring that questions related to the accuracy or integrity of any part of the work are appropriately investigated and resolved.

Open Access Statement: This is an Open Access article distributed in accordance with the Creative Commons Attribution-NonCommercial-NoDerivs 4.0 International License (CC BY-NC-ND 4.0), which permits the noncommercial replication and distribution of the article with the strict proviso that no changes or edits are made and the original work is properly cited (including links to both the formal publication through the relevant DOI and the license). See: https://creativecommons.org/licenses/by-nc-nd/4.0/.

\section{References}

1. Wang MJ. Prof. Johan F. Vansteenkiste: bring immunotherapy to frontline therapy in order to cure more patients. Asvide 2018;5:917. Available online: http://www. asvide.com/article/view/29063

(Science Editor: Molly J. Wang, SHC, shc@amegroups.com) 